\title{
Hydrological extremes in the Aksu-Tarim River Basin: Climatology and regime shift
}

\author{
Hui Tao ${ }^{1} \cdot$ Hartmut Borth $^{2} \cdot$ Klaus Fraedrich $^{3} \cdot$ Andrea Schneidereit $^{4} \cdot$ Xiuhua Zhu $^{2}$
}

Received: 11 July 2014 / Accepted: 4 May 2015 / Published online: 25 June 2015

(C) The Author(s) 2015. This article is published with open access at Springerlink.com

\begin{abstract}
Precipitation data between 1961 and 2010 from 39 meteorological stations in the Tarim River Basin are analyzed to classify and investigate hydrological drought and wetness conditions by using the standardized precipitation index (SPI). The leading time and spatial variability of hydrological drought has been investigated by applying a principal component analysis and Varimax rotation to the SPI on a time scale of 24 months. The results suggest that the western basin is characterized by a clear tendency towards wetter conditions after the middle of the 1980s, which results from an increase in the number of wet extremes and can be considered as a regime shift. Subdividing the period of analysis into two parts (1961-1986 and 1987-2010) this change can be clearly seen in a shift of the probability distribution function of precipitation events. Composite analyses of monthly mean geopotential height fields and wind fields of the ERA-40 data set show that enhanced wetness in the Tarim River Basin after the middle of 1980s is closely related to cyclonic anomalies on the European continent and circulation anomalies over mid-latitude of the Northern Hemisphere. Further correlation analysis between the principal components of SPI and large circulation indices shows that hydrological extremes
\end{abstract}

Hartmut Borth

hartmut.borth@uni-hamburg.de

1 State Key Laboratory of Lake Science and Environment, Nanjing Institute of Geography and Limnology, Chinese Academy of Sciences, Nanjing 210008, China

2 Center for Earth System Research and Sustainability, CliSAP, University of Hamburg, 20144 Hamburg, Germany

3 Max Planck Institute for Meteorology, 20144 Hamburg, Germany

4 Leibniz-Institute of Atmospheric Physics, 18225 Kühlungsborn, Germany in the Tarim River Basin correlate with indices related to the polar vortex and subtropical high.

Keywords Standardized precipitation index $\cdot$ Aksu-Tarim River Basin · Drought and wetness · Regime shift

\section{Introduction}

In the semi-arid regions in Central Asia water supply is extremely important (Barlow and Tippett 2008; Sorg et al. 2012). The water availability in this area is the limiting factor for the distribution of vegetation and the related biogeochemical fluxes (Aizen et al. 2007). Recently, there has been a debate on the apparent increase in large parts of the planet of dry events and on the possible physical causes of these phenomena (Bonaccorso et al. 2003; Sheffield et al. 2012; Dai 2013; Yu et al. 2014). Seen from a more general point of view the Tarim River Basin is very interesting for investigations of Earth's climate history, since, due to the geographical setting, small shifts of the Monsoon system on the one hand and of the mid-latitude cyclone belt on the other hand lead to large changes in the local hydrological cycle. Indeed paleorecords from the western margin of the Tarim Basin show that at least during the last 4000 years the climatic conditions oscillate on a quite regular basis between wet and dry periods (Zhao et al. 2012). Each of these periods can last several hundred years. More interestingly wet periods correlate quite well with so-called Bond events, i.e. cool periods in the North-Atlantic, during which ice-drift can be observed as far south as Britain (Bond et al. 1997). Such a correlation can also be found during the socalled little ice age, where a cool climate in Europe goes in parallel with a cool and humid climate in the Tarim Basin as sediment cores from the Bosten Lake show (Chen et al. 
2006). Recent studies of statistical correlation patterns in global atmospheric reanalysis data sets of the Northern Hemisphere clearly demonstrate the existence of circumglobal teleconnections between climate regimes on different continents (Ding and Wang 2005; Conversi et al. 2010; Zhu et al. 2011).

In the more recent past (second half of the 1980s) a substantial change in the hydrological regime is observed in north-western China and especially in the Tarim Basin. A period of warm and dry climate changes towards a more humid and warmer climate (e.g. Tao et al. 2014). Some investigations connect the moistening very generally to an intensification of the hydrological cycle in a warming climate (Shi et al. 2007; Chen et al. 2008). On the other hand the recycling rate in the Tarim River Basin is at most $14 \%$ during the rainy season ( $\mathrm{He}$ and $\mathrm{Lu}$ 2013), which is, e.g. much less than the basin-wide $34 \%$ in the amazonian River Basin (Trenberth 1999). It is still an open question to what extent the more humid conditions can be attributed to feedback processes increasing the local water vapor recycling rate and to what extent changes of the dominating largescale water vapor convergence over the Tarim River Basin are responsible for the trend. In the NCEP global reanalysis data set the annual mean water budget is dominated by far by the zonal water vapor convergence (Wu et al. 2012). A net moisture export is only found towards the south. Since the hydrological cycle is represented only partly in the global reanalysis data sets (Hagemann et al. 2005), this picture might change in future if better high resolution atmospheric simulations are available (Mannig et al. 2013).

To assess objectively the characteristics of the hydrological cycle in the Tarim River Basin and to connect it in a consistent manner to the mid-latitude atmospheric circulation the occurrence of drought and wetness is deduced from time series of precipitation using the standardized precipitation index (SPI). Even if the hydrological conditions are not completely homogeneous over all meteorological stations considered, the basin wide signal is still strong enough. The SPI is introduced by McKee et al. (1993) to define and monitor drought and wetness. For example, a drought assessment in Europe shows that the SPI exhibits a downward trend or a not statistically significant change over most areas (Lloyd-Hughes and Saunders 2002; Bordi et al. 2006, 2009; Vicente-Serrano et al. 2014). Moreover, the SPI has been used to quantify deficits in water resource and as drought monitoring tool in many other countries and regions for example: Greece (Livada and Assimakopoulos 2007); China (Wei et al. 2003; Wu et al. 2007; Chen et al. 2009; Bordi et al. 2004); India (Patel et al. 2007); Iran (Raziei et al. 2008). The major strength of SPI stems from the possibility to compare drought events in regions and areas with different climates, taking into account multiple time scales. The standardized precipitation-evapotranspiration index (SPEI) combines the SPI with the Palmer drought severity index (PDSI) which has been used by Tao et al. (2014) to assess drought and wetness variability in the Tarim River Basin during 1961-2010. They find a significant shift from drier to wetter conditions in 1986 confirming the analyses cited above.

The structure of this paper is as follows: In Sect. 2 the geographical setting of the Tarim Basin is introduced, the methods of time series analysis are described and the climatology (variability, trend and extremes) of the hydrological cycle is derived using precipitation data of 39 meteorological stations of the period between 1961 and 2010. The spatial variability and regime shift, composite analysis of geopotential height and wind fields, as well as hydrological extremes are presented in Sect. 3 together with a connection to atmospheric large-scale circulation indices. In Sect. 4 results and possible considerations for future studies on the topic are discussed.

\section{Climatological setting, methodology and data}

\subsection{Climatological setting}

The Tarim River Basin (Fig. 1) is located in the Northwest of China and covers an area of $102 \times 10^{4} \mathrm{~km}^{2}\left(35^{\circ}-43^{\circ} \mathrm{N}\right.$, $74^{\circ}-90^{\circ} \mathrm{E}$ ) and is one of the world's largest closed hydrological drainage systems without outflow (Tao et al. 2011). The basin is surrounded by high mountain chains like the Tien Shan, Eastern Pamir, KunLun and Karakorum. The mountains act as barrier and make the understanding of the mechanisms behind the water vapor transport quite complex (Wu et al. 2012). Glaciers, snowmelt and precipitation in the surrounding mountains are the main source of the Tarim River runoff (Chen et al. 2006). The water vapor potentially available stems from the Asian Monsoon systems and from the ocean and lakes in the west of Asia (Dai et al. 2007). Traditionally the climate regimes in the Tarim River Basin are mainly understood as the interplay of the southwestern branch of the Siberian anticyclonic circulation and the cyclonic activity from the west (Aizen et al. 1997). More recent investigations show that albeit the main path of water vapor crosses the western and northwestern boundary of the Tarim Basin the biggest annual net contribution of water vapor enters through the eastern boundary (Wu et al. 2012). The hydrological cycle is characterized by a rainy season in summer and a dry season in winter (for more details see below).

Precipitation data at 39 meteorological stations are provided by the Climate Center of Xinjiang Province for the period of 1961-2010. The stations are irregularly distributed, particularly sparse in high mountainous and desert areas (Fig. 1). Figure 2 shows the climatological year for 
Fig. 1 Map of meteorological stations used in this investigation

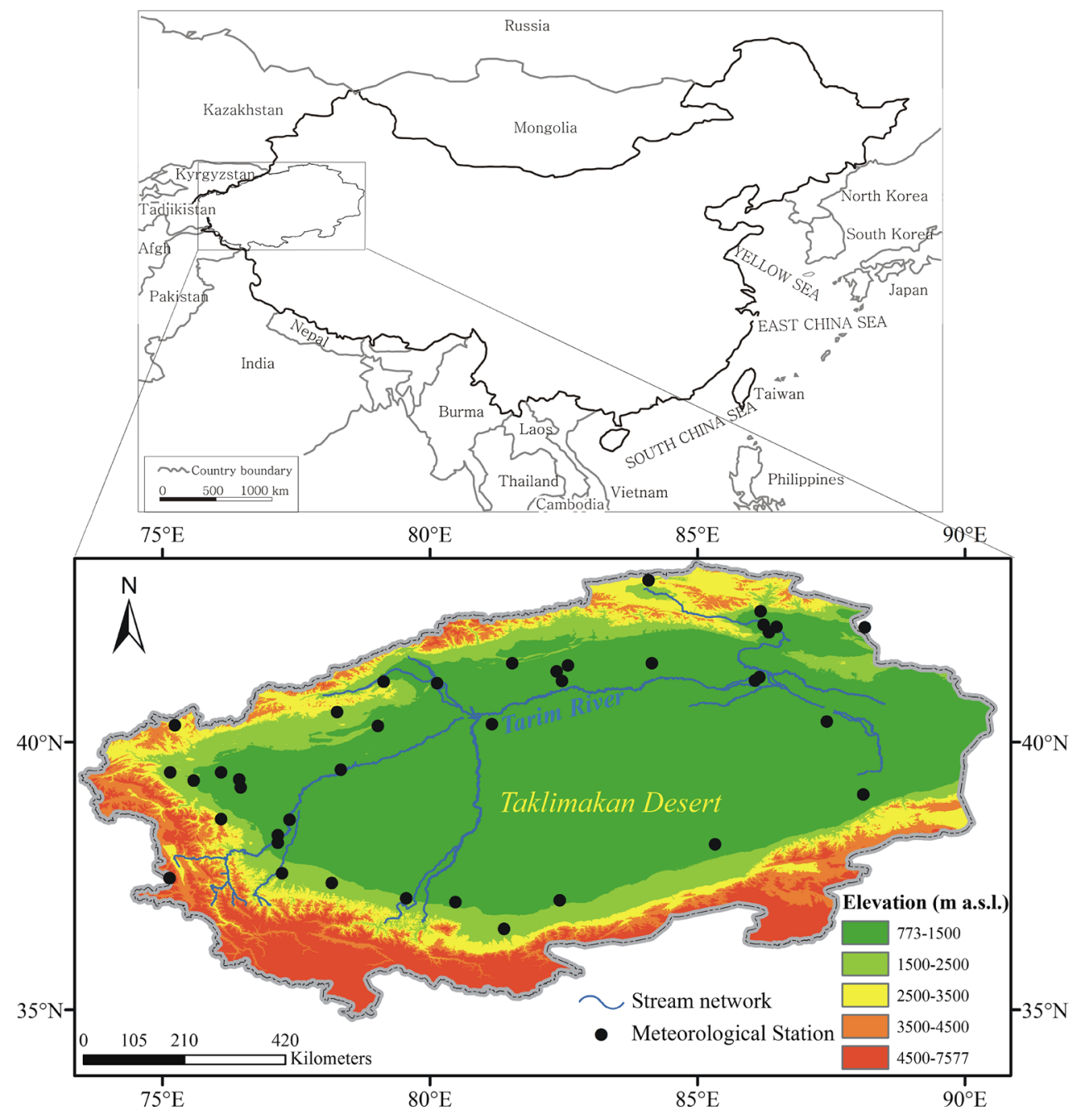

some representative stations. For all stations a more or less well-pronounced rainy and dry season is found. The amount of precipitation strongly depends on the altitude. The maximum average monthly precipitation during the rainy season varies from less than $10 \mathrm{~mm}$ for low stations in the south to up to nearly $70 \mathrm{~mm}$ for elevated stations in the north. The maximum precipitation occurs in June to August and the minimum in November to January. Over the year the rain is distributed more evenly in the North West and more concentrated in the rainy season in the southeast. The exponential distributions of daily precipitation of all stations show a higher probability of no precipitation or trace precipitation in eastern compared to western stations.

The average annual precipitation depends strongly on the elevation of the station. It ranges from about $30 \mathrm{~mm}$ for stations in the central plain to nearly $300 \mathrm{~mm}$ for stations in mountainous areas above $3000 \mathrm{~m}$. In elevated areas the precipitation can exceed $300 \mathrm{~mm}$ per year and falls mostly in form of snow. The steep gradients of elevation and the high interannual variability of precipitation make the hydrologic and climatic feedbacks in the Tarim River Basin quite different from those in lower-elevations or in humid regions of China and other regions in the world. However, in China, most of the related studies focus on the eastern monsoon region (Bothe et al. 2010; Zhang et al. 2014a, b), the effect of volcanoes (Zhang et al. 2012), whereas drought and wetness in the Tarim River Basin is rarely connected with large-scale mid-latitude circulation (Tao et al. 2014).

\subsection{Methodology}

\subsubsection{Standardized precipitation index (SPI)}

The SPI is a standardized and multi-scale index and allows objectively comparing dry/wet conditions of regions with different hydrological regimes. Typical time scales used are 1-, 3-, 6-, 12-, and 24-month (SPI-1, SPI3, SPI-6, and SPI-24, respectively). The first step is to determine the probability density function of precipitation and the cumulative probability. The next step is to 

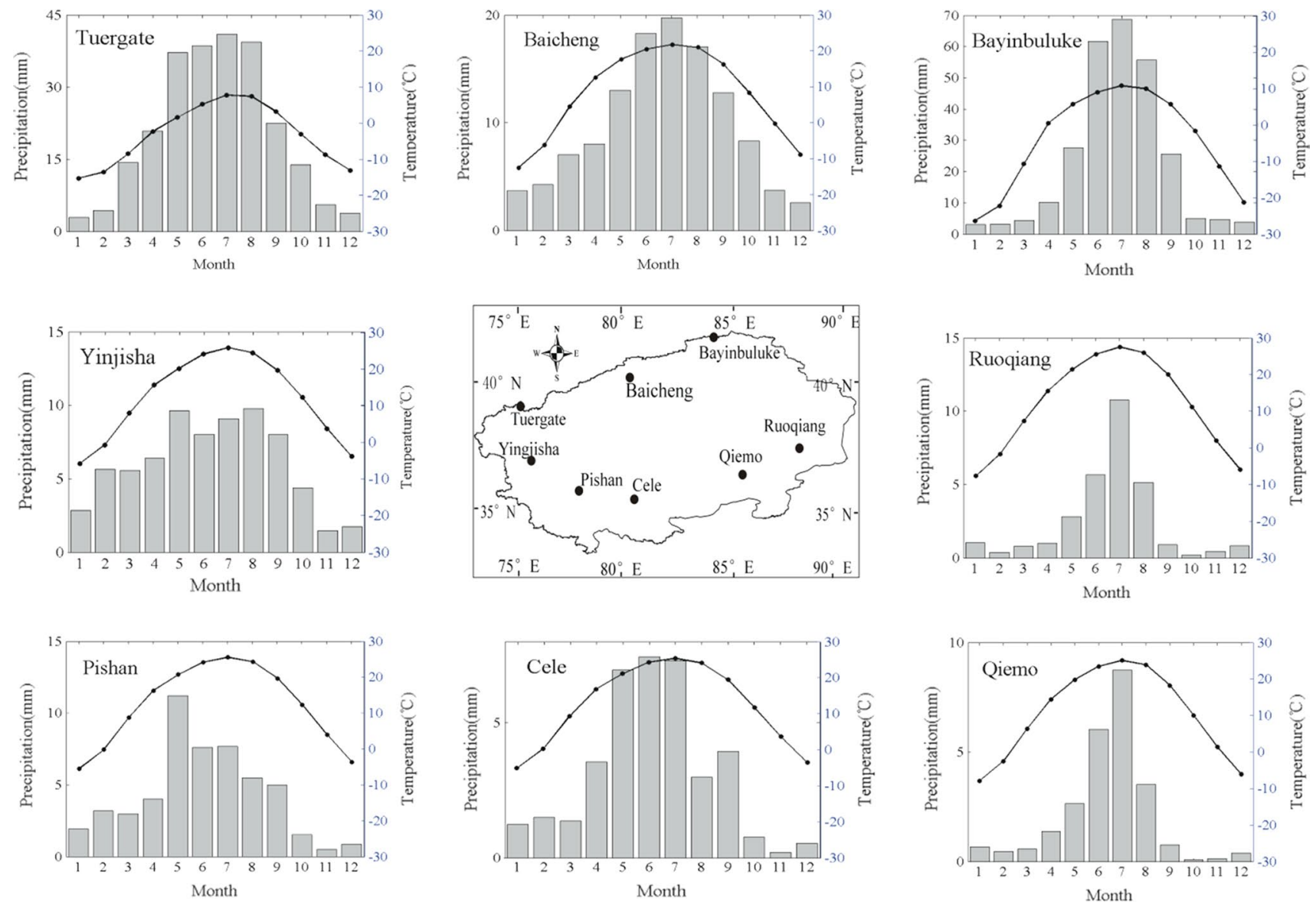

Fig. 2 Intrannual cycle of precipitation (bars) and temperature (dotted line) of selected stations across the Tarim River Basin for the period 1961-2010

Fig. 3 The transformation of precipitation to SPI is illustrated by solid lines and arrows: a gamma distribution $(\Gamma$, left $)$ is transformed to the standard normal distribution $(\Phi$, right)

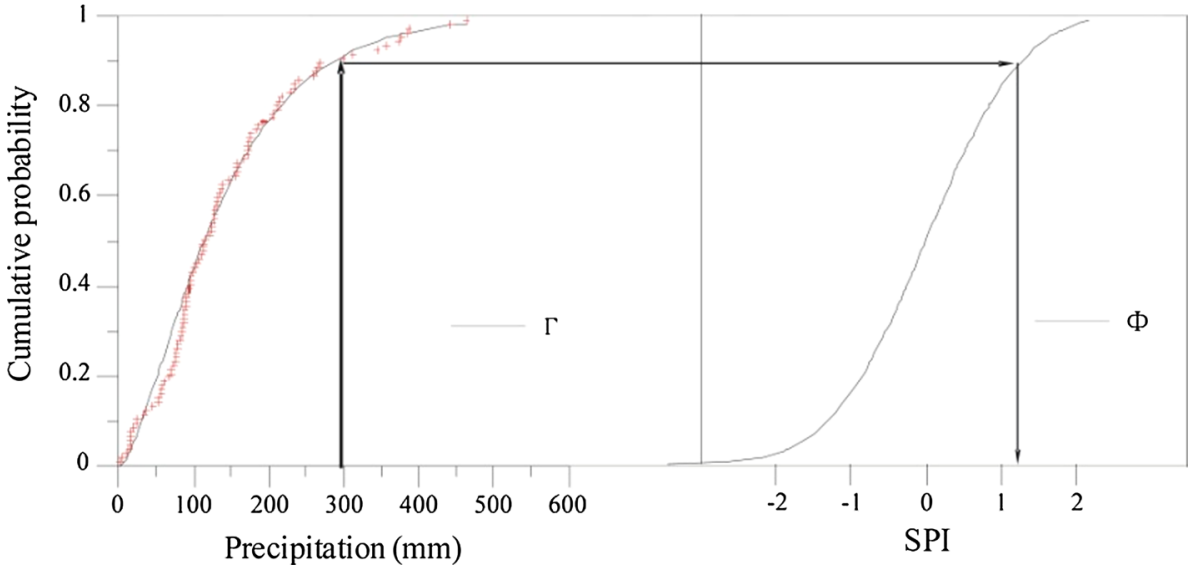

apply the inverse normal function, with zero mean and unit variance, to compute the cumulative probability, which leads to the SPI.

In this study, the common used gamma distribution is selected to fit the monthly precipitation data. Detailed steps for computing the SPI by gamma distribution can be found in Lloyd-Hughes and Saunders (2002). The computation is based on an "equal probability transformation" (Fig. 3). Namely, the probability of being less than a given value of the obtained cumulative probability should be the same as the probability of being less than the corresponding value of the normal distribution. The classification of dry and wet 
Table 1 Classification of standardized precipitation index (SPI)

\begin{tabular}{llc}
\hline SPI & Classification & Probability $(\%)$ \\
\hline SPI $\geq 2.0$ & Extremely wet & 2.3 \\
$2.0>$ SPI $\geq 1.5$ & Severely wet & 4.4 \\
$1.5>$ SPI $\geq 1.0$ & Moderately wet & 9.2 \\
$1.0>$ SPI $\geq-1.0$ & Near normal & 68.2 \\
$-1.0 \geq$ SPI $>-1.5$ & Moderate drought & 9.2 \\
$-1.5 \geq$ SPI $>-2.0$ & Severe drought & 4.4 \\
SPI $\leq-2.00$ & Extreme drought & 2.3 \\
\hline
\end{tabular}

events intensities resulting from SPI computation and the corresponding probabilities of occurrence of each severity are shown in Table 1.

\subsubsection{Principal component analysis}

The principal component analysis (PCA), sometimes referred to as Empirical Orthogonal Function (EOF) analysis, has been applied to SPI-12 and SPI-24, respectively. The PCA is a standard statistical method based on the computation of the eigenvalues and eigenvectors of either the correlation matrix or the covariance matrix of a given variable. The spatial patterns, properly normalized (divided by their Euclidean norm and multiplied by the square root of the corresponding eigenvalues), are the so-called 'loadings', which represent the correlations between the variable and the corresponding principal component time series.

The PCA model for any variable $j$ may take the form:

$Z_{j}=a_{j 1} F_{1}+a_{j 2} F_{2}+a_{j 2} F_{2}+\cdots+a_{j m} F_{m} \quad(j=1,2, \ldots, m)$,

with $F_{l}, F_{2}, \ldots, F_{m}$ the principle components, $Z_{j}$ the normalized precipitation records, $a_{j k}$ the regression weights (loadings) of the $k$ th principal component (Ogallo 1989). In this study, we further apply an orthogonal rotation based on varimax criterion to obtain more spatially localized features (Raziei et al. 2014; Bonaccorso et al. 2003).

\subsubsection{Regime shift detection}

A 'regime shift' is characterized by an abrupt transition from one quasi-steady climatic state to another, which leads to new regime conditions, and its transition period is much shorter than the length of the individual epochs of each climatic state (Sayaka and Hanawa 2002). To determine the regime shift of SPI time series we apply a non-parametric statistical test, the Mann-Whitney-Pettitt (MWP) method developed by Pettitt (1979). The MWP method works as follows: Consider a time series $\left\{\mathrm{X}_{1}, \mathrm{X}_{2}, \ldots, \mathrm{X}_{\mathrm{n}}\right\}$ of length $\mathrm{n}$. Let $\mathrm{t}$ be the time of the most likely turning point. Two samples, $\left\{X_{1}, X_{2}, \ldots, X_{t}\right\}$ and $\left\{X_{t+1}, X_{t+2}, \ldots, X_{n}\right\}$ can then be derived by dividing the time series at time $t$. An index, $U_{t}$ is derived by

$U_{t}=\sum_{i=1}^{t} \sum_{j=t+1}^{n} \operatorname{sgn}\left(x_{i}-x_{j}\right)$

where $\operatorname{sgn}(x)=1$ if $x>0, \operatorname{sgn}(x)=0$ if $x=0$ and $\operatorname{sgn}(\mathrm{x})=-1$ if $\mathrm{x}<0$. The time $t$ where $\mathrm{U}_{\mathrm{t}}$ is maximum is chosen as the turning point. The approximate significance probability $p(t)$ for a change point (Hoppe and Kiely 1999) is given by

$p(t)=1-\exp \left(\frac{-6 U_{t}^{2}}{n^{3}+n^{2}}\right)$

The change point at time $t$ has a significance level of $\alpha$ if the probability $\mathrm{p}(\mathrm{t})$ exceeds $(1-\alpha)($ Chen et al. 2009).

\subsection{Data}

This study employs monthly precipitation data of 39 stations for the period 1961-2010 achieved from the National Climate Center. To explore the causes for the increase in wet events in the Tarim River Basin, the $500 \mathrm{hPa}$ geopotential height field and wind fields ( $\mathrm{u}$ - and v-component) are taken from the ERA-40 reanalyses (Uppala et al. 2006) obtained from the World Data Center for Climate (WDCC) in Germany. This data set is given on pressure levels and has a $2.5^{\circ} \times 2.5^{\circ}$ horizontal resolution. For further understanding of the atmospheric circulation behind the hydrological extremes, 74 large-scale circulation indices treated by the Climate Diagnostics and Prediction Division of the National Climate Center are selected to identify the key indices that may be linked with hydrological extremes in the Tarim River Basin. Detailed calculation of each index can be found in Zhao (2000).

\section{Spatial and temporal variability of hydrological extremes}

Even if the meteorological stations considered are located on very different sites the signal of hydrological extremes is still clearly present if the average over all stations is taken. To identify the spatial patterns and the temporal behavior of the hydrological extremes, SPI-12 and SPI-24 are used and subject to the PCA (for details see second part of Sect. 2.1).

We find that the PCA based on the SPI-12 and SPI-24 give similar results, so that in the following we only show the results based on the SPI- 24 .

The eigenvalues and corresponding accumulated variance contributions of the PC scores of the SPI-24 (Fig. 4) suggest that the eigenvalues decrease quickly to zero and 


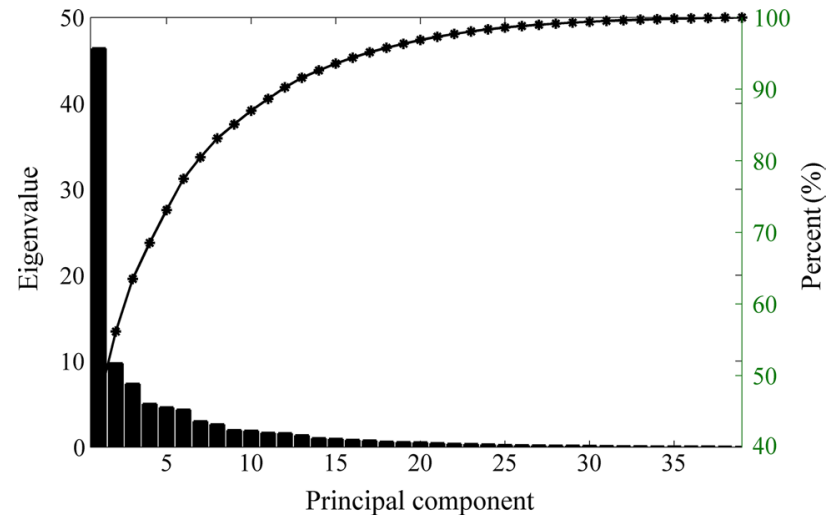

Fig. 4 The eigenvalues and corresponding accumulated variance contributions of the PCs scores of the SPI-24

the first eigenvalue at each time scale is well separated from the rest of the modes. The first 10 eigenvectors of the SPI-24 explain about $88 \%$ of the total variance. The loading pattern (Fig. 5a) shows a maximum in the west of the Tarim River Basin, that is, high positive and spatially homogeneous correlations between hydrological drought variability in those regions and the corresponding first principal component score.

The second loading (Fig. 5b) explains about $11 \%$ of the total variance and displays a pattern almost complementary to that of the first loading. Since the first loading pattern of the SPI-24 (Fig. 5a) is positive in the western part, those regions are affected more by wet conditions during the last 30 years.

\subsection{Regime shift}

The variations of the first principal component of SPI24 (Fig. 6) reveal a clear shift after the middle of 1980s towards wetter conditions, superposed by strong interannual fluctuations. Therefore, in the last 30 years the Tarim River Basin has been more affected by wet events, although there was an obviously dry event during the eighties of last century, which pushes the principal component score toward a negative value.

The turning point of the SPI-24 is determined by the Mann-Whitney-Pettitt (WMP) method. About half of the

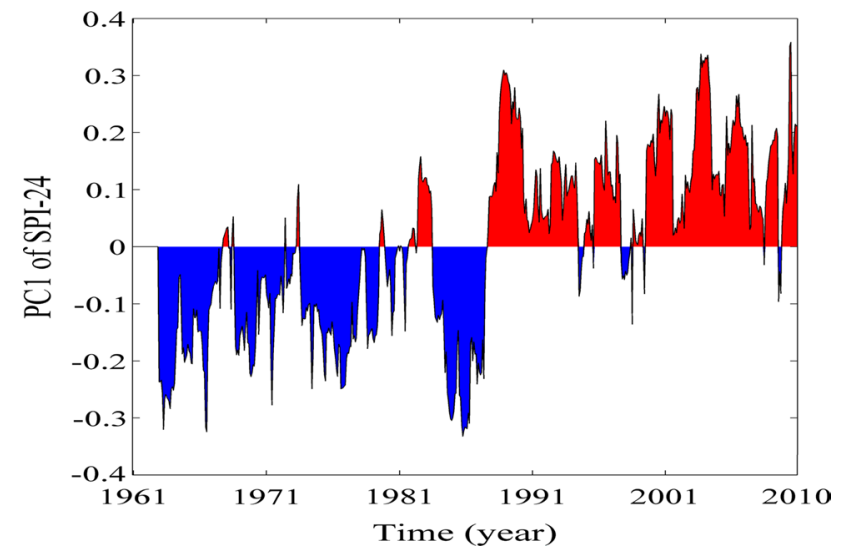

Fig. 6 The time behavior of the first standardized principal component score of the SPI-24

39 stations experience the change during the years 1987 and 1988, which is consistent with the change point of climate change in northwest of China identified by Shi et al. (2007). These stations are uniformly distributed over the Tarim River Basin. However especially in the south some of the stations reveal a turning point around the year 2000 .

Since precipitation is the primary factor controlling the formation and persistence of drought conditions (LloydHughes and Saunders 2002), the change point of averaged monthly precipitation over the whole Tarim River Basin is also investigated. The change point is identified to be January 1986. Figure 7 shows the probability distribution of seasonal precipitation for the observation periods 19611986 and 1987-2010, respectively. An obvious shift of the distribution of monthly precipitation can be identified in all seasons except in autumn. An increase in the location parameter can be observed in summer (Fig. 7a) and a slight change in the scale parameter in winter (Fig. 7b).

\subsection{Composite analysis}

The regime shift analysis of the SPI time series of last section shows a turning point for the year 1987 for most stations in the Tarim River Basin. To explore the causes for the increase in wet events in the Tarim River Basin after 1987 we took the difference of the averaged geopotential heights at $500 \mathrm{hPa}$ of the months of January and July during the
Fig. 5 The first (a) and second (b) loading pattern of the principal components of the SPI-24
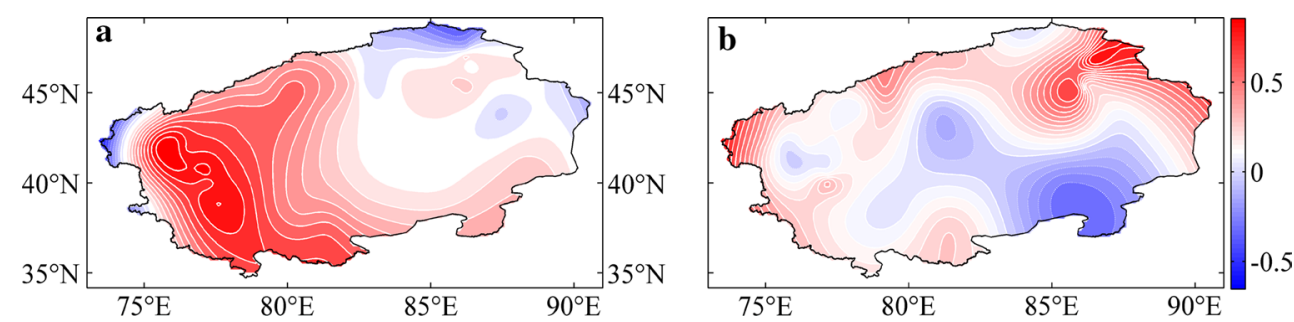
Fig. 7 Probability distribution of monthly precipitation in the Tarim River Basin during 1961-1986 (grey line) and 1987-2010 (black line) in a summer and $\mathbf{b}$ winter
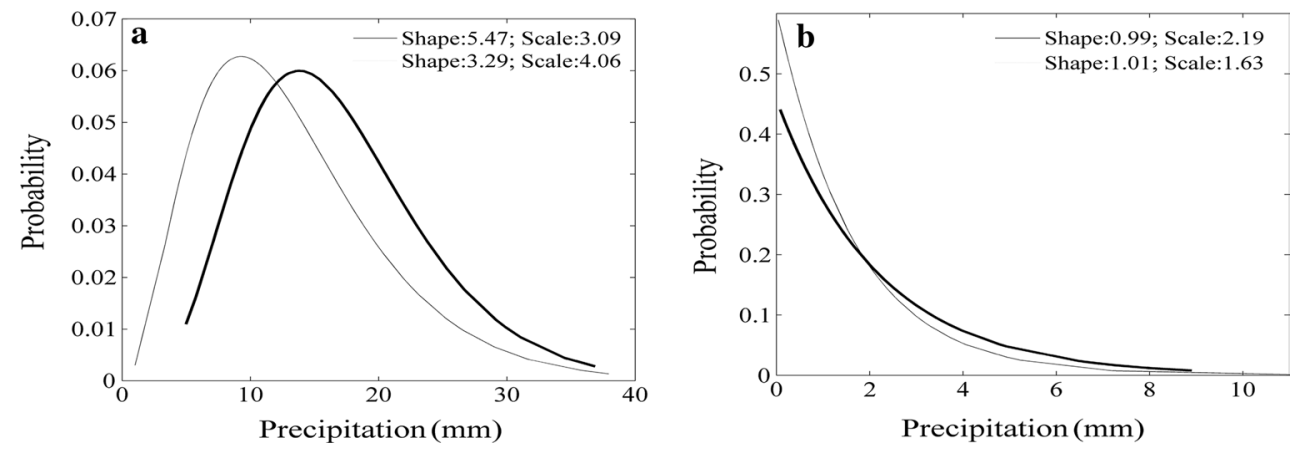

periods of 1987-2002 and 1961-1986. The height differences in January, show a strong anticyclonic $(+)$ center on the European continent located south of a cyclonic center $(-)$ in the north of Central Asia and the Bering Strait (Fig. 8a), implying an increased air inflow towards the Tarim River Basin from the west during the wetter period 1987-2002.

The most prominent anomaly in July (Fig. 8b) is a strong cyclonic center (-) over the Arctic and Siberia. In addition there are several smaller anticyclonic anomalies over central Europe, western Siberia and the coastal region of the west Pacific. The strong cyclonic center implies an intensified and larger polar vortex during the period of 1987-2002 as compared to the periods of 19611986. There are several less well-pronounced anticyclonic anomalies $(+)$ in middle latitudes. Together with the polar cyclonic anomalies they imply an increased westward moisture transport. Indeed, based on NCEP/NCAR reanalysis dataset, Zhao et al. (2006) also find that in summer (JJA), there is an intensified ridge extending from Lake Aral to the Ural Mountains and a trough between the middle Asian region and Lake Balkash in the upper troposphere in the wetter period mentioned above. Aizen et al. (1997) argue that a weakening of the local mountain anticyclonic activity and displacement to the northwest of the Siberian anticyclone strengthen westerly cyclonic advection to the peripheral, low-altitude, Tien Shan regions. This causes increased precipitation, and a weakening of surface air temperature increases in altitudinal belts below $2000 \mathrm{~m}$ in the northern and western Tien Shan.

Figure $8 \mathrm{a}$ also demonstrates an obvious annular wind component over the European continent, indicating a stronger European anticyclone during 1987-2002 for the month January. An obviously strong cyclonic circulation can be found in the Aral Lake and Balkhash Lake (Fig. 8b). Its coexistence with the anomalous anticyclone over Siberia and Europe suggests the connection of atmospheric variability over Siberia and Europe and circulation anomalies over mid-latitude Asia. The cyclonic circulation anomalies over the Aral Sea and Balkhash Lake during 1987-2002 may contribute to the strengthening of ascending flow and an increase of summer precipitation in the Tarim River Basin. In contrast, the anticyclonic circulation over Europe may contribute to the strengthening of descending flow and drought in Europe during 1987-2002.

\subsection{Possible link with large-scale circulation indices}

In order to better understand the possible drivers of hydrological extremes, Pearson's correlation coefficients (Pearson 1920) are computed for the 74 large-scale circulation indices and the first principal component PC1 of the SPI-24
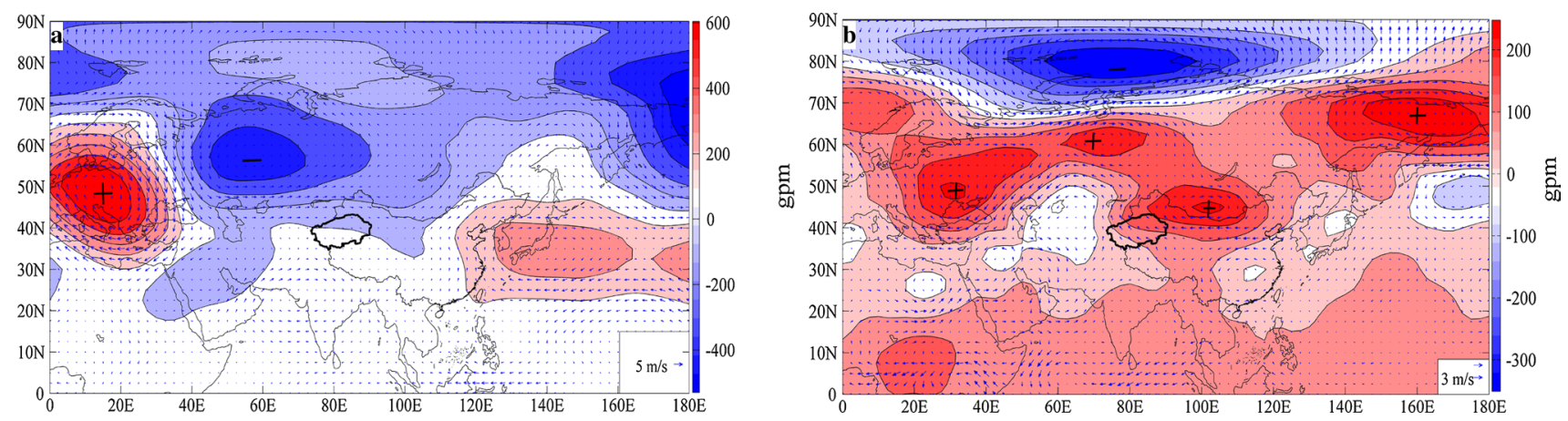

Fig. 8 Difference of averaged winds and geopotential height on $500 \mathrm{hPa}$ between the periods of 1987-2002 and 1961-1986 for January (a) and July (b) 
(PC1-24). In general, the PC1-24 is negatively correlated with polar vortex related indices, and positively correlated with subtropical high related indices. The indices related to the polar vortex in the Atlantic and Europe sector (SPVAES and APVAES) show the most significant correlation. It is noteworthy that Bothe et al. (2012) also demonstrated that distinct upstream anomalies in the North Atlantic sector appear to influence the development of the persistent circulation over Eurasia and subsequently the pluvial anomalies in Central Asia.

\section{Discussion and conclusion}

The present analysis of the SPI time series from 1961 to 2002 in the Tarim River Basin shows a regime shift. Wet events become more frequent after the middle of 1980s. The PCA analysis shows high (low) values in the western (eastern) areas of the Tarim River Basin. The same conclusions can be drawn for SPI-12. Tao et al. (2014) find the same regime shift using a different precipitation index, i.e. the standardized precipitation-evapotranspiration index (SPEI). This shows that the regime shift is quite robust with respect to the time-scale and precipitation index used. Based on the NCEP-NCAR reanalysis data it is shown that in the warm season the midlatitude atmospheric circulation plays an important role by transporting moisture from the east into the Tarim River Basin during the wetter conditions after 1986.

Similar conclusions can be drawn by composite analyses with large-scale atmospheric fields from the ERA reanalysis set. They reveal a strong influence of the geopotential height fields and wind fields over the European continent, identifying different atmospheric circulation patterns before and after the middle of 1980s for January and July, respectively. A link is suggested between interannual fluctuations of large-scale circulation indices. Hydrological extremes are negatively correlated with polar vortex related indices and positively with subtropical high related indices. Based on the maximum/minimum flow from the headwater of the Tarim River Basin, Wang et al. (2014) concluded that different circulation indices may influence the trends of hydrological extremes. The area of the polar vortex in North American and the area of the Northern Hemisphere polar vortex show the most significant correlation with a 1-day maximum flow and a 1-day minimum flow in Aksu River, respectively. In Hotan River, the most significant correlated climate indices with the 1-day maximum and minimum flow were the Southern Oscillation index and the area of Northern American Subtropical High, respectively. The area of the polar vortex in the Atlantic and European Sector show significant relationships with the 1-day minimum flow in Yarkand River. Therefore, special attention should be paid on the polar vortex in the Atlantic and Europe sector.
To find the physical mechanisms which are responsible for the statistical correlations between climate shifts in the NorthAtlantic-European sector and Central Asia it is very attractive to connect hydrological extremes in the Tarim Basin to the large-scale spatio-temporal patterns of the mid-latitude atmospheric circulation, see Borth et al. (2015). Future studies require more in-depth analyses into the underlying dynamical processes and the spatial and temporal aspects of relationships between large-scale circulation variability and hydrological extremes over the Tarim River Basin.

Acknowledgements This study was supported by the German Science Foundation DFG (cluster of excellence, Integrated Climate System Analysis and Prediction (EXC 177) and project, Climate change and water resources in western China (Aksu-Tarim), PAK 393) and the National Natural Science Foundation of China (Nos. 41330529 \& 41101023). Hui Tao gratefully acknowledges receipt of a DAAD scholarship (German Academic Exchange Service). Support by the Max Planck Fellowship is appreciated (KF). AS was supported by the German Science Foundation (DFG, under Grand PE474/7-1/2) as part of the PANDOWAE project. Reviewers and editor's valuable comments are appreciated.

Open Access This article is distributed under the terms of the Creative Commons Attribution 4.0 International License (http://creativecommons.org/licenses/by/4.0/), which permits unrestricted use, distribution, and reproduction in any medium, provided you give appropriate credit to the original author(s) and the source, provide a link to the Creative Commons license, and indicate if changes were made.

\section{References}

Aizen VB, Aizen EM, Kuzmichonok VA (2007) Glaciers and hydrological changes in the Tien Shan: simulation and prediction. Environ Res Lett. doi:10.1088/1748-9326/2/4/045019

Aizen VB, Aizen EM, Melack JM, Dozier J (1997) Climatic and hydrologic changes in the Tien Shan, Central Asia. J Clim 10:1393-1404

Barlow MA, Tippett MK (2008) Variability and predictability of Central Asia river flows: antecedent winter precipitation and largescale teleconnections. J Hydrometeorol 9:1334-1349

Bonaccorso B, Bordi I, Cancelliere A, Rossi G, Sutera A (2003) Spatial variability of drought: an analysis of the SPI in Sicily. Water Resour Manag 17:273-296

Bond G, Showers W, Cheseby M, Lotti R, Almasi P, deMenocal P, Priore P, Cullen H, Hajdas I, Bonani G (1997) A pervasive millennial-scale cycle in North Atlantic holocene and glacial climates. Science 278:1257-1266

Bordi I, Fraedrich K, Jiang JM, Sutera A (2004) Spatio-temporal variability of dry and wet periods in eastern China. Theor Appl Climatol 79:81-91

Bordi I, Fraedrich K, Petitta M, Sutera A (2006) Large-scale assessment of drought variability based on NCEP-NCAR and ERA-40 re-analyses. Water Resour Manag 20:899-915

Bordi I, Fraedrich K, Sutera A (2009) Observed drought and wetness trends in Europe: an update. Hydrol Earth Syst Sci 13:1519-1530

Borth H, Tao H, Fraedrich K, Schneidereit A, Zhu X (2015) Hydrological extremes in the Aksu-Tarim River Basin: Mid-latitude dynamics. Clim Dyn. doi:10.1007/s00382-015-2650-x 
Bothe O, Fraedrich K, Zhu XH (2010) The large-scale circulations and summer drought and wetness on the Tibetan Plateau. Int $\mathbf{J}$ Climatol 30:844-855

Bothe O, Fraedrich K, Zhu XH (2012) Precipitation climate of Central Asia and the large-scale atmospheric circulation. Theor Appl Climatol 108:345-354

Chen F, Huang X, Zhang J, Holmes JA, Chen J (2006) Humid little ice age in arid Central Asia documented by Bosten Lake, Xinjiang, China. Sci China Ser D 49(12):1280-1290

Chen X, Wu JL, Hu Q (2008) Simulation of climate change impacts on streamflow in the Bosten Lake Basin using an artificial neural network model. J Hydrol Eng 13:180-183

Chen ST, Kuo CC, Yu PS (2009) Historical trends and variablity of meteorological droughts in Taiwan. Hydrol Sci J 54:430-441

Conversi A, Fonda Umani S, Peluso T, Molinero JC, Santojanni A, Edwards M (2010) The Mediterranean Sea regime shift at the end of the 1980s, and intriguing parallelisms with other European Basins. PLoS ONE 5(5):e10633. doi:10.1371/journal. pone. 0010633

Dai AG (2013) Increasing drought under global warming in observations and models. Nat Clim Change 3:52-58

Dai XG, Li WJ, Ma ZG, Wang P (2007) Water-vapor source shift of Xinjiang region during the recent twenty years. Prog Nat Sci 17(5):569-575

Ding Q, Wang B (2005) Circumglobal teleconnection in the Northern Hemisphere summer. J Clim 18:3483-3505

Hagemann S, Arpe K, Bengtsson L (2005) Validation of the hydrological cycle of ERA40. Reports on earth system science 10, Max Planck Institute for Meteorology, Hamburg

He H, Lu GH (2013) Precipitation recycling in Tarim river basin. J Hydrol Eng 18(11):1549-1556

Hoppe H, Kiely G (1999) Precipitation over Ireland-observed change since 1940. Phys Chem Earth B24:91-96

Livada I, Assimakopoulos VD (2007) Spatial and temporal analysis of drought in Greece using the standardized precipitation index (SPI). Theor Appl Climatol 89:143-153

Lloyd-Hughes B, Saunders MA (2002) Drought climatology for Europe. Int J Climatol 22:1571-1592

Mannig B, Müller M, Starke E, Merkenschlager C, Mao W, Zhi X, Podzun R, Jacob D, Paeth H (2013) Dynamical downscaling of climate change in Central Asia. Glob Planet Change 110:26-39

McKee TB, Doesken NJ, Kleist J (1993) The relationship of drought frequency and duration to time scales. In: Proceeding of the 8th conference on applied climatology, Anaheim, CA, American Meteorological Society, pp 179-184

Ogallo LJ (1989) The spatial and temporal patterns of the east African seasonal rainfall derived from principal component analysis. Int J Climatol 9:145-167

Patel NR, Chopra P, Dadhwal VK (2007) Analyzing spatial patterns of meteorological drought using standardized precipitation index. Meteorol Appl 14:329-336

Pearson K (1920) Notes on the history of correlation. Biometrika 13:25-45

Pettitt AN (1979) A non-parametric approach to the change-point problem. Appl Statist 28(2):126-135

Raziei T, Bordi I, Pereira LS (2008) A precipitation-based regionalization for western Iran and regional drought variability. Hydrol Earth Syst Sci 12:1309-1321

Raziei T, Martins DS, Bordi I, Santos JF, Portela MM, Pereira LS, Sutera A (2014) SPI modes of drought spatial and temporal variability in Portugal: comparing observations, PT02 and GPCC gridded datasets. Water Resour Manag. doi:10.1007/ s11269-014-0690-3
Sayaka Y, Hanawa K (2002) Regime shifts found in the Northern Hemisphere SST field. J Meteorol Soc Jpn 80(1):119-135

Sheffield J, Wood EF, Roderick ML (2012) Little change in global drought over the past 60 years. Nature 491:435-438

Shi YF, Shen YP, Kang ES, Li DL, Ding YJ, Zhang GW, Hu RJ (2007) Recent and future climate change in Northwest China. Clim Change 80:379-393

Sorg A, Bolch T, Stoffel M, Solomina O, Beniston M (2012) Climate change impacts on glaciers and runoff in Tien Shan (Central Asia). Nat Clim Change 2:725-731

Tao H, Gemmer M, Bai YG, Su BD, Mao WY (2011) Trends of streamflow in the Tarim River Basin during the past fifty years: human impact or climate change? J Hydrol 400:1-9

Tao H, Borth H, Fraedrich K, Su B, Zhu X, Bai Y (2014) Drought and wetness variability in the Tarim River Basin and connection to large-scale atmospheric circulation. Int J Climatol 34:2678-2684

Trenberth E (1999) Atmospheric moisture recycling: role of advection and local evaporation. J Clim 12:1368-1381

Uppala et al (2006) The ERA-40 re-analysis. Quart J R Meteorol Soc 131:2961-3012

Vicente-Serrano SM et al (2014) Evidence of increasing drought severity caused by temperature rise in southern Europe. Environ Res Lett 9:044001

Wang HJ, Chen YN, Li WH (2014) Hydrological extreme variability in the headwater of Tarim River: links with atmospheric teleconnection and regional climate. Stoch Environ Res Risk Assess 28:443-453

Wei J, Zhang QY, Tao SY (2003) Characteristics of atmospheric circulation anomalies during persistent droughts in North China for last two decades. J Appl Meteorol 14(2):140-151

Wu H, Svoboda MD, Hayes MJ, Wilhite DA, Wen F (2007) Appropriate application of the standardized precipitation index in arid locations and dry seasons. Int J Climatol 27:65-79

Wu YP, Shen YP, Li BL (2012) Possible physical mechanism of water transport over Tarim Basin. Ecol Complex 9:63-70

Yu MX, Li QF, Hayes MJ, Svoboda MD, Heim RR (2014) Are droughts becoming more frequent or severe in China based on the Standardized Precipitation Evapotranspiration Index: 19512010? Int J Climatol 34:545-558

Zhang D, Blender R, Fraedrich K (2012) Volcanoes and ENSO in millenium simulation: global impacts and regional reconstructions in East Asia. Theor Appl Climatol 111:437-454

Zhang L, Zhu XH, Fraedrich K, Sielmann F, Zhi XF (2014a) Interdecadal variability of winter precipitation in Southeast China. Clim Dyn 43:2239-2248

Zhang L, Zhu XH, Fraedrich K, Sielmann F, Zhi XF (2014b) Interannual variability of winter precipitation in Southeast China. Theor Appl Climatol. doi:10.1007/s00704-014-1111-5

Zhao ZG (2000) Summer drought/flood and the environmental field in China. Meteorological Press, Beijing (In Chinese)

Zhao BK, Cai CX, Yang LM, Wang H (2006) Atmospheric circulation anomalies during wetting summer over Xinjiang Region. J Glaciol Geocryol 28(3):434-442 (In Chinese)

Zhao K, Li X, Dodson J, Atahan P, Zhou X, Bertuch F (2012) Climatic variations over the last 4000 calyr BP in the western margin of the Tarim Basin, Xinjiang, reconstructed from pollen data. Palaeogeogr Palaeoclimatol Palaeoecol 321-322:16-23

Zhu X, Bothe O, Fraedrich K (2011) Summer atmospheric bridging between Europe and East Asia: influences on drought and wetness on the Tibetan Plateau. Quat Int 236(1):151-157 